\title{
AN INVESTIGATION INTO THE QUALITY OF SERVICE DELIVERED BY THE SOUTH AFRICAN POLICE SERVICE IN THE NORTH RAND, GAUTENG
}

\author{
LEAH MOFOMME \\ NEIL BARNES \\ Department of Human Resource Management \\ Rand Afrikaans University
}

\begin{abstract}
An investigation was conducted into the level and quality of service delivered by the SAPS in the Client Service Centres (CSC). Quality was measured in terms of the principles of batho pele. The concept of ubuntu was introduced to see how it could be used to enhance these principles. A customer service model was developed and used to evaluate the quality of service rendered. Interviews were conducted with staff, customers and managers. The results of the study showed that employees of the SAPS do not experience internal quality. The customers also do not receive service of a good quality as the principles of batho pele were not applied.
\end{abstract}

\section{OPSOMMING}

'n Ondersoek is geloots, met betrekking tot die kwaliteitsvlakke van diens lewering by die Suid Afrikaanse Polisiediens se Kliente Diens Sentrums. Die kwaliteit van diens lewering word gemeet aan die maastawwe van die batho pele beginsels. ' $\mathrm{n}$ Kliente diens model is vir hierdie doel ontwerp om die kwaliteit van dienste gelewer te bepaal. Die resultate van hierdie studie toon dat die werknemers van die SAPD ondervind nie interne kwaliteit nie en hul nie die beginsels van batho pele implementeer nie.

According to Karmen (1984:133), police are the first representatives of the Criminal Justice System, with which victims of crime come into contact. Karmen (1984:125) quotes Reilly (1981) who said that the one word, which can be used to describe how the Criminal Justice System treats victims of crime and witnesses, is "badly". He also quotes Heinz (1982) who said that the painful insensitivity of the Criminal Justice System towards victims of crime is a 'crime' which goes largely unnoticed and it is committed daily across the nation.In terms of the National Crime Prevention Strategy (NCPS) (1996), crime violates the individual's basic human rights and the experience is traumatic. Williams 1999:52 supports this by indicating that victims of crime may be engulfed by feelings of fear, guilt, depression and posttraumatic stress.

The Police are expected to be sensitive towards victims of crime, comfort them, show empathy and provide good quality service. They must provide a more victim-friendly service (Update on National Crime Prevention Strategy 1997:7). This will help restore a sense of equilibrium in the crime victim. It will also enable the victim to heal and move on with the least possible harm. The Strategic plan for the SAPS $2002-2003$ provides a code of conduct for the South African Police Service. The Police undertake to render service of a high quality responsibly and effectively, and to continue improving it. The 1997 White Paper on Transforming Public Service Delivery prescribed that public services must render quality service and put people (customers) first. It identified eight principles of service delivery that are intended to put people first. These batho pele principles are consulting customers about their needs, setting service standards, access to services, courtesy, information, openness and transparency, remedy failures and best possible value for money.

\section{DYNAMICS OF THE PROBLEM}

Groenewald (2001:38) cites Merton who identified certain dysfunctions that are present in bureaucratic institutions, which affect the organisation's efficiency:

Requests for copies should be addressed to: L Mofomme, Department of Human

Resource Management, RAU, PO Box 524, Auckland Park, 2006
The conservative nature of bureaucracies makes it difficult for the organisation to become flexible and adjust to changes in the external environment. Bureaucracy results in trained incompetence. Routine work leads to a mental state of work psychosis, where an individual displays certain preferences and antipathies and emphasises some aspects of his job at the expense of others. Excessive conformity to rules may result in the organisation giving first priority to observing rules and regulations at the expense of satisfying needs of the customer. The existence of a formal structure for maintaining discipline results in relationships that are depersonalised. The organisation becomes hypersensitive to all forms of criticism, whether external or internal.

Marks (2000:145), indicates that the police must demonstrate the ability to adapt to changed environments and aspire to perform best, as they are the most public face of the State. He said that the police operate on a strict ranking system and there is a strong emphasis on rules and regulations enforced through specific disciplinary measures. They also have a distinct and discernible occupational culture or what is called "cop culture" (Reiner 1992 as cited by Marks 2000:145). According to McLaughlin \& Muncie (2001:74) the "cop culture" arises from group socialization, the work environment and institutional routine.

These features and dysfunctions make it difficult for police organisations to adapt to change. This results in police officials who are resistant to change as they are used to stability and strictly enforced ways of behaviour.

Marks (2000:146) argues that the police are more comfortable with maintaining the status quo and will generally give new names to old practices, limit themselves to traditional mechanisms, such as new training and new policies, and claim that they have changed.

\section{THE IMPORTANCE OF CUSTOMERS}

According to Jenkins (1997:12), customers are an important stakeholder group that must be brought into the strategic thinking of an organization. Customers are seen as a catalyst for change and it is therefore important to create and sustain a 
dialogue with them. Gerson (1992:34) indicates that organizations must recognize customers for their loyalty and continued business by sending them gifts and thank you cards. Their needs and expectation must be addressed beyond the average. Horovitz (2000:57) indicates that organizations often see complaining customers as the enemy. The author adds that customers who formally complain have, on average, already made two attempts to be heard before they finally sent a letter or phone. Kessler (1996:58) says that customers who complain are heavily committed as they take their time, effort and energy to complain. They can be transformed into ambassadors for the organization. It is important that customers know where to address their complaints and that procedures are made very easy. The name and contact details of the manager must be available for customers at all times (Horovitz 2000:65).

\section{THE SERVICE-PROFIT CHAIN}

According to Edvardsson \& Gustavsson (2003:148), research on customer satisfaction has focused on the customer, drivers of customer satisfaction, and what the customer perceives to be quality. This has been done at the expense of work satisfaction of the employees. The authors say that emphasis was placed on characteristics of employees such as attitudes, competence and behavior. They quote Schlesinger and Heskett (1991) who argued that customer satisfaction is rooted in employee satisfaction. They refer to external service quality, which leads to customer satisfaction and loyalty, as well as internal service quality, which drive employee satisfaction. Employee satisfaction drives external quality, which in turn drives internal quality service.

Heskett, Jones, Loveman, Sasser \& Schlesinger (1994:164) refer to the service-profit chain to indicate the relationship between internal quality and organizational success. The needs of employees must be met for them to do a good job (Bergman \& Klefjö 1994:24). Internal quality also requires that employees as internal customers, be informed about the company's progress on customer satisfaction. This will make them identify with the objectives and programs of the company and be motivated to achieve them. Employees who experience internal quality become loyal to the organization and remain in the company for long. The final product in this chain of events is organizational success and growth (Heskett et al 1994:165). The authors further indicate that leadership underlies the success of the chain. A leader, who understands how the service-profit chain works, will strive to achieve internal quality.

\section{ENHANCING BATHO PELE THROUGH UBUNTU}

According to Mbigi (1997:2), ubuntu "is a literal translation for collective personhood and collective morality". He says that the concept is best expressed by the Xhosa proverb, which says that people are people through others. Mbigi (1997:3) indicates that ubuntu is a concept that is uniquely African and emphasises concern for people and being good. Broodryk (1998:28) indicates that $u b u n t u$ means humanness. The main pillars of $u b u n t u$ are intense caring and sharing attitudes. These values will enable a police official to show more courtesy towards customers.

\section{THE PROBLEM STATEMENT}

The SAPS needs people who can deliver quality service. Customer satisfaction depends on the value of services provided by employees. The latter can only deliver quality services if they are also satisfied in their work. The present research question therefore could be stated as follows:

Does the level and quality of the service delivered by the SAPS satisfy the needs and expectations of the community (customer) of the North Rand? The context of this question is that if the police apply the eight principles of batho pele, then the needs and expectations of their customers will be met.

\section{RESEARCH DESIGN}

The research design, which was utilised in this study, is phenomenological. It enabled the researcher to understand the experiences of the customers with regard to the service delivered by the SAPS.

In order to test data collection methods, the researcher did a pilot study at Kwa-Thema police station, which is outside the Area of North Rand. Participatory observation was used as a method of data collection as the researcher wanted to study the experiences of human beings in their natural environment. The researcher visited all 14 police stations in the North Rand. She spent four hours in the Client Service Centre (CSC) of each station, interacting with employees of the SAPS and observing interactions between the police and members of the community, as well as interactions among police members. Conversations and interactions were analysed.

\section{Measuring instrument}

Qualitative interviews were conducted with customers who had received service from the police. Interviews were also conducted with employees of the SAPS who work in the CSC and station management. In order to ensure quality, the researcher prepared specific questions that helped to give structure to the interviews. These consisted of main questions, probes and follow-up questions. Three questionnaires were developed; for the station manager, the client and the employees who work in the CSC. The questionnaires consisted of different sections that were meant to obtain information on principles of batho pele and ubuntu, members experiences and managers perceptions.

\section{INTERNAL QUALITY}

Internal quality was measured in terms of whether employee loyalty and achievement are rewarded; what influences how important they feel in the workplace; what influences the satisfaction of their needs and expectations, whether employees are empowered and whether management asks them for feedback and suggestions on service delivery improvement. The researcher also determined how managers measured employee performance to see whether incentives are awarded based on performance.

\section{RESULTS}

Members from nine police stations indicated that their management does reward loyalty, while those from five police stations said loyalty is not rewarded. All managers indicated that they do reward customer champions.

All employees interviewed indicated that they feel important when the community and their commanders appreciate their efforts and hard work. They indicated that their needs and expectations are satisfied when colleagues, managers and the community appreciate them. They also indicated that work conditions could be improved and their needs and expectations could be satisfied if they received additional and proper facilities. Members from seven stations added that they need more supportive and committed managers who recognize them for their good work. Only one said that managers must give them rest days as a reward for good work.

All members interviewed indicated that when a customer is not satisfied with the service rendered, they refer him/her to their superior. If the superior is not available such as after hours, they request the person to come back when the supervisor will be 
available. Only six of the members interviewed indicated that they attended the customer service course and they felt that it was very useful for CSC personnel. They indicated that customer satisfaction could be improved if more members attended the course. Eight had not attended the customer service course and did not know what it entails. Only one of the eight indicated that customer service could be improved through the customer service course. The rest quoted more resources as the solution to improving customer service. All employees interviewed seem to feel that giving feedback on investigations is not their job; it is the responsibility of detectives. They therefore only refer customers to detectives.

Members from seven stations indicated that their station commanders do ask them for feedback and suggestions on service delivery. Employees from the remaining seven stations indicated that their station commanders never spend time with them in the CSC and never ask them for any suggestions. They indicated that they only see the station commissioners in the CSC when they come to check registers. However, when the researcher interviewed managers, they all mentioned that they do interview employees in the CSC about their work.

All members interviewed indicated that the Performance Enhancement Programme (PEP) is used to measure performance on a quarterly basis.

\section{CUSTOMER SATISFACTION}

Customer satisfaction was assessed in terms of the eight principles of batho pele.

\section{Accessibility}

Accessibility was assessed in terms of whether the police stations are easy to find and within reach for the customers, accessibility to people with disabilities and the elderly, and whether the station has victim friendly facilities.

The researcher observed that six of the police stations in the North Rand have direction boards from the main roads. Eight of the police stations do not have any directional boards from the main roads. All the police stations in the North Rand are accessible to the disabled and the elderly. All clients interviewed indicated that it was easy for them to find the police stations because they live within the station precinct. Only one customer indicated that although she knew where the station is, she had to take two taxis to get there. This was seen as an inconvenient and expensive exercise.

All stations in the North Rand have created facilities where customers with sensitive cases are interviewed. Only three stations have fully established victim support centres.

\section{Value for money}

Value for money was assessed in terms of courtesy, interpersonal skills and competence of employees.

All the customers interviewed indicated that there was someone to help them when they arrived at the station and employees of the SAPS knew what to do in order to assist them. They reported that employees were able to express themselves and to write statements where necessary. Of all the customers interviewed, only one indicated that he had called the station before and could not be assisted. He then decided that he will never call the station but will go there whenever he needs assistance from the station.

Out of all the customers interviewed, four came to open case dockets, two reported accidents and five went to certify documents, two needed sworn statements and one old lady had previously opened a case docket and came to enquire when the police would arrest the suspect. Two of the four who had opened case dockets were happy with the service they received in the CSC, two were unhappy that the police did not go out to arrest the suspects immediately.

The elderly lady who came to enquire when the police would come to arrest the suspect indicated that the former is always there and continues to harass her. She was then told to wait for the patrol van so that she could go with the police and show them the suspect. The rest of the customers (nine) were happy with the assistance they received from the police.

\section{Service standards}

Service standards were assessed in terms of their existence, whether they are known and respected by all employees and whether customers' experiences meet their expectations.

The researcher observed that all 14 police stations visited did not have vision/mission statements on customer satisfaction. No service standards were displayed in the CSC or anywhere in the station. Only four stations had the batho pele principles displayed in the CSC. All employees interviewed did not know the values of the SAPS. They also indicated that their stations did not have their own policy on customer service or specific customer service standards.

All customers interviewed indicated that they expect the police to be available at all times when needed and to assist them without delay. Three of the customers added that they also expect the police to go out and arrest suspects whose whereabouts are known. They also indicated that their expectations were not met as the police only opened dockets and did not go further and arrest the suspects. Eleven customers indicated that the police officials in the CSC did meet their expectations.

\section{Courtesy}

Courtesy was assessed in terms of how employees interact with customers, how they address them and how they respond to them. The question of ubuntu was considered in terms of whether employees show respect and empathy.

All customers interviewed indicated that employees of the SAPS in the CSC did not greet them nor introduce themselves; neither did they ask them their names. The researcher also observed that the members in the CSC did not greet the customer. They only approached the counter and asked whether they can help. Some even called customers by shouting "next!". All customers interviewed indicated that the police officials must be more friendly and polite than they currently are.

The researcher observed that members did show some level of ubuntu in that they were helpful, but they did not show any empathy and/or kindness. When a person reported a crime or an accident, they only took prescribed forms and started writing down the facts. They did not share any of the customer's feelings.

Nine of the station commissioners also indicated that members do not have good communication skills. They said that members do not place themselves in the position of the customer and try to understand their problem. One station commissioner said that members like to refer customers to other stations and to social workers instead of helping them. One of the nine station commissioners said that members do not understand procedures of domestic violence cases and therefore refer people to other institutions. Five of the station commissioners said that members have good communication skills but there is room for improvement. Three of these managers said that members received training when they attended the customer service course and two said they were never trained and use natural skills. 
All customers reported that employees of the SAPS had good communication skills, as they were able to take statements and help them. Some of the customers were happy that members of the SAPS were able to help them in their own language.

\section{Information}

Information was assessed by determining whether customers are informed of the processes and procedures that will follow after they visited the station.

The customers who came to certify documents and to obtain affidavits did not need additional information from the police. The four who came to open case dockets and the two customers who reported accidents indicated that the police had informed them of the processes that they would follow and what they had to do in the mean time. However, they were told that the detectives would contact them, they were not told when that would happen. The last customer indicated that the police had explained the procedures to her but nothing happened as they said.

\section{Remedy failures}

This was assessed in terms of whether customers are given an opportunity to evaluate the service they received and what is done about that. The SAPS' procedures to register complaints were looked at. The research also assessed how customer satisfaction is measured and whether results are used to improve service delivery.

All the customers interviewed indicated that they were not asked to evaluate the service they received; neither did they see a feedback/comments form. At one of the police stations, the researcher found notices in the CSC requesting all customers to fill in the opinion poll forms next to the suggestion box before they left the station. No opinion poll forms were available and all the members in the CSC did not know what forms those were. One station commissioner produced a service evaluation form, which he printed from the computer. It appears as if it was once used but the practice has since been discontinued, as CSC employees were not aware of the evaluation form. Neither were such forms available in the CSC. Out of all the customers interviewed, only one knew how to register a complaint against the police. This customer is involved in policing, as he is a member of the Community Policing Forum (CPF). When members of the SAPS were asked what they do when a customer is not satisfied with the service, they all said they refer him/her to the superiors. None indicated that they give them an option to register a complaint against the police and/or explained the procedures. All customers interviewed suggested that the police must ask them to evaluate services received. Methods suggested varied from short evaluation forms, short interviews by supervisors, to electronic devices where the customer punches in comments. Service Delivery and Improvement Programme (SDIP) files were perused. These were found to contain only the station plans. No documentation on measuring service and/or initiatives to improve it could be found. All the station commissioners reported that they have not done any SDIP activities at all this year.

All the managers indicated that they were not happy that service delivery is not measured.

The researcher observed that all 14 police stations did not have a notice informing customers who to contact if they are not satisfied with the service.

\section{Consultation}

Consultation was assessed in terms of whether communities are consulted about the services they require, and whether they are involved in policing. The existence and functioning of Community Police Forums (CPF) at each station was also assessed.
Only one out of fourteen customers interviewed said he was a member of the CPF and attended meetings regularly. He said that CPF's could be improved if police management showed more interest and commitment. All the other customers could not comment on the question. Thirteen customers indicated that the police had never consulted them about the services they need. The other was the CPF member who felt that he is consulted.

All the station commissioners reported that they involve the community in policing through the CPF. They also attend meetings that are arranged by the community, street committees, SANCO, etc. Their school monitoring unit and captain crime stop are also used to visit schools and youth centers to tell them about crime. It is during these meetings that the police hear about the problems and needs of the community.

\section{Openness and transparency}

Openness and transparency were assessed in terms of site visits and open days organized by the police for members of the community.

All customers interviewed indicated that they had never received invitations for a site visit or open day. Five of the customers indicated that they had seen and heard the police speak about crime and their achievements, but not necessarily from their station. Three customers said they usually read about their station from the local newspapers. They said that the stories are mostly about crime, crime hints and police members' achievements.

As indicated above, station commissioners reported that they get an opportunity to inform the community about police initiatives by attending meetings when invited by the community. Only one station commander indicated that the station and the CPF usually arrange information sessions for the community to inform them about crime. This station also has a website and a monthly newsletter which is distributed to all the residents. Contact numbers of the CPF and the CSC are printed on the newsletter.

\section{DISCUSSION}

It appears that customers of the SAPS do not expect a high quality service from members in the client service centre. They accept the pure basics that they require from the police. They do not seem to measure employees in terms of the principles of batho pele but on whether they can do the basics of opening dockets, certifying documents, etc. From the results of the study, it appears that members of the SAPS in the CSC believe that service delivery can only be improved through more and better resources.

Initiatives to reward employees and to measure customer satisfaction are started but are generally not sustained Employees are rewarded with certificates and floating trophies. The Service Delivery Improvement Programme (SDIP) was last done during 2002 but no record could be found of what was measured at that time. The Police in the North Rand are not happy that they do not measure whether customers are satisfied with the service received or not. It appears that employees in the CSC are not empowered to handle customer complaints. They refer these to their seniors and make no follow-up as to whether the customer was eventually satisfied. The CSC is open every day for 24 hours and this is where members of the community go for assistance. The research found that out of 71 complaints registered against the Police for the period January 2003 to August 2003, 33 relate to poor investigation or no feedback on progress of investigations. However, members of the SAPS who work in the CSC are not able to give full assistance and feedback to customers who come to enquire. The customer is only told who the 
investigating officer is and whether the case docket is still open or closed. $\mathrm{He} / \mathrm{She}$ is then referred to the detectives for more information. This sometimes means that the customer must come back the next day and they still cannot assure him/her that the detective will be available. There is no "fix-it-now" approach due to the "it is not my job" custom.

The research indicated that most customers found it difficult to understand what value for money means in the context of policing. The researcher had to restructure the question and ask whether customers were satisfied with the service they received. Customers are not encouraged to complain formally. No employee of the SAPS in the CSC indicated that they gave customers who were not happy with the service an option to register a complaint against the police. Procedures and necessary forms for registering a complaint against the police are not available in the CSC. Officers who work office hours only keep them. Except for one station, there are no notices in the CSC informing members of the community who to contact if they are not happy with the service.

A discrepancy was found between the report of employees and the response of managers. All managers reported that they interact with employees and reward loyalty, while only $50 \%$ of the employees interviewed said that their commanders interact with them in the CSC and (9) indicated that managers do reward loyalty.

The community arranges most community meetings and they notify the police. The latter then get an opportunity to address them about crime: tendencies, hints, etc. They do not address them about their needs or give them information about customer satisfaction and levels of quality they can expect. No open days or site visits were arranged by the police up to the time of the collection of data.

The results of the research indicated that more people go to the police station for administrative processes than to open cases. Those who open cases expect the police to go out and arrest suspects if customers tell them where to find them.

It seems as if members of the SAPS distance themselves from the feelings of the community. They only do the physical work but do not seem to get emotionally involved by showing empathy and supporting the victim. They do not genuine concern and interest in the customer. They only stick to the facts and completing forms/documentation. This makes it difficult for them to render quality service and they seem to be sticking to the old ways of doing things.

Customers do not seem to expect the police to be friendly and courteous towards them. However, when asked how courtesy could be improved, all customers said the police must be friendlier and greet them.

It appears that the police make use of CPF structures to consult the community about their needs. However, emphasis seems to be on crime and not on softer issues of service delivery.

Cop-culture can make the police expect the community to treat them badly, so they develop a defence against the community. This creates division, as the police may not see themselves as part of the community. This can have a disabling effect on service delivery. Managers play a major role in changing the culture of the organisation. Police managers must use the "copculture" to transform the organisation.

\section{RECOMMENDATIONS}

It is recommended that the South African Police Service (SAPS) adopt the customer service model described below in order to improve customer satisfaction in the Client Service Centre (CSC).

\section{INTERNAL QUALITY: STRIVE FOR INTERNAL CUSTOMER SATISFACTION}

Internal quality must be developed through applying the principles of batho pele to the employees of the SAPS. Management must treat employees with respect, involve them in decision-making and empower them. Subordinates must feel that every job is important. Employees who feel important in their work will be loyal and remain in the SAPS for longer periods. Therefore, expertise will not be lost.

\section{STRIVE FOR EXTERNAL CUSTOMER SATISFACTION}

Happy employees will provide quality service to external customers. They will be able to apply the principles of batho pele and the values of ubuntu.

The SAPS currently uses Community Police Forums (CPF) to consult the community about crime problems. The functioning of CPF's must be enhanced and utilised optimally in terms of the manual of the SAPS (1997). They must be used as a point to report complaints about poor service.

The SAPS management must develop standards on customer service in consultation with all employees. These must be communicated to all employees and customers and be displayed in client service centres.

Police officers must be more courteous towards the customers. They must learn to introduce themselves to customers. They must remember the names of customers and address them by their name. They must be more polite and show respect when calling customers to help them. They must develop a sharing and caring attitude (ubuntu).

Customers must be invited for a site visit to the CSC, allowed to work with the police and to give feedback on their experiences with regard to service delivery.

Customers must be encouraged to evaluate services and complain. Opinion forms/questionnaires must be developed and kept in the CSC where customers can see them. A note must be placed in the CSC informing customers about the questionnaires, complaint forms and who to contact when they are not happy with the service.

Members of the SAPS must give the best possible value for money by handling requests and enquiries to the satisfaction of the customer. The latter must not be sent to different people. CSC personnel must make the necessary enquiries and give feedback to the customer.

\section{ORGANISATIONAL SUCCESS}

Internal customer satisfaction will lead to better quality service being rendered to the community. This will lead to satisfied customers who will appreciate employees of the SAPS and thus enhance feelings of worth and satisfaction among employees. The SAPS as an organisation will be able to achieve its vision/mission and values with regard to customer service.

\section{GOOD LEADERSHIP AND MANAGEMENT}

Good leadership and management are prerequisites for the success of the customer service model. The management of the SAPS must model correct behavior in the way they treat their subordinates and customers. Managers must recognise the efforts and achievements of employees by giving rewards and celebrating "champions". They must also drive customer service programmes through continuous in-service training. 
In conclusion, it appears, from the study that customers do not have very high expectations of the police. They were only happy with the administrative duties performed. The quality of the service rendered in terms of Batho pele is very poor. Employees of the SAPS do not experience internal quality and therefore do not provide quality service to customers.

\section{REFERENCES}

Bergman, B. \& Klefsjö, B. 1994. Quality: from Customer needs to Customer Satisfaction. London: McGraw-Hill Book Company

Broodryk, J. 1998. Managing the ubuntu way: four teats of a cow. Management Today, April 1998, 28-31.

Edvardsson, B., Thomasson, B. \& Øvretveit, J. 1994. Quality of service: making it really work. New York: McGraw-Hill Book co.

Gerson, R.F. 1993. Measuring customer satisfaction. Crisp publication Inc: USA.

Groenewald, B.J.J. The Service side of Policing. Presentation at Institute for Municipal Law Enforcement (IMLE) conference. 23 - 24 August 2001: WESTERN CAPE.

Heskett, J.L., Jones, T.O., Loveman, G.W., Sasser, Jr.,W.E. \& Schlesinger,L.A. 1994. Putting the Service-Profit Chain to Work. Havard Business Review. 164-174.

Horovitz, J. 2000. The Seven Secrets of Service Strategy. PRENTICE-HALL: GREAT BRITAIN
Karmen, A. 1984. Crime Victims: An Introduction to Victimology. California: BROOKS/COLE PUBLISIHING COMPANY.

Kessler, S. 1996. Measuring and managing customer satisfaction: Going for the Gold. ASQC QUALITY PRESS: WISCONSIN.

Losardo, M.M. \& Rossi, N.M. 1993. At the Service Quality Frontier: a handbook for managers, consultants and other pioneers. ASQC Quality Press: WISCONSIN.

Marks, M. 2000. Transforming Robocops? A case study of police organisational change. Society in Transition, 31 (2): 144 -161.

Mbigi, L. 1997. UBUNTU: The African Dream in Management. Randburg: Knowledge resources (PTY) LTD.

McLaughlin, E. \& Muncie, J. 2001. Controlling Crime. Second edition. Sage publications: London.

Williams, B. 1999. Working with Victims of Crime: Policies, Politics and Practice. London \& Philadelphia: Jessica Kingsley Publishers Notice 1459 of 1997.

Minister of Safety \& Security. Draft Policy Document: CHANGE. 1994.

White Paper on Public Service Delivery (Batho Pele White Paper). Government Gazette No. 18340. Government Printers: PRETORIA.

National Crime Prevention Strategy. May 1996.

National Instruction 1/2000. Service Delivery Improvement. March 2000. South African Police Service.

Strategic plan for the South African Police Service: 2002 - 2005

Update on National Crime Prevention Strategy. Vol. 2 No.1 of 1997. Draft Policy Document. 1994. Minister of Safety and Security. 